\title{
Redesign Logo Duta Minang Wedding Organizer And Planner
}

\author{
Melisa Suardi $^{1}$, Wilma Sriwulan ${ }^{2}$, Syafwandi $^{3}$ \\ ${ }^{12) 3)}$ Program Pascasarjana ISI Padangpanjang \\ Jl. Bahder Johan Guguk Malintang, Padang Panjang-Kota Padang Panjang, Sumatera Barat 27118 \\ Email: chanuk2891@gmail.com ${ }^{1)}$, sriwulanwilma@gmail.com ${ }^{21}$, syafwandi1960@ gmail.com ${ }^{3)}$
}

\begin{abstract}
A company must have a logo as an identity so that people can be known as consumers to consume the products they sell. Redesign the logo at an Ambassador Minang Wedding Organizer and Planner company, which is located at Jl. Rajawali No 09 Padang. done if the old logo does not meet the requirements, including: (1) it is not feasible to be used on the application media; (2) changes in the company's vision and mission; (3) the use of logos that do not function as they should; (4) the ineffectiveness of the logo to be recognized by the public; and (5) to the inconsistency in the form of logos to be used in media that will be a promotional place for companies. Just like the Ambassador of Minang, Wedding Organizer and Planner, who indeed left a logo on several media applications, and favored the name of the company just to be known by the public and applied the name to several print media. So it is necessary to design a logo regarding Ambassador Minang Wedding Organizer and Planner. In the design of the Ambassador of Minang Wedding Oragnizer and Planner logo, the designer uses the AIDA logo method of analysis as a promotional tool that must attract attention, get and encourage interest, generate desire, and produce action on the product. As the identity of the company, the logo requires a design that is simple, easy to remember, flexible and dynamic. The logo as a visual identity to create product productions in the form of the target audience's mind and the creation of a new logo will build the image of the community to the Ambassador of Minang, Wedding Organizer and Planner. The purpose of designing the design of the Ambassador of Minang Wedding Organizer and Planner to achieve the wishes of the Minang Ambassador Wedding Organizer and Planner became a service company with complete and sought-after equipment and equipment in the city of Padang. The redesign of the company's logo can form a new character from the company that is accompanied by changes in the new vision and mission that are used today.
\end{abstract}

Keywords : Design, Logo, Ambassador Minang Wedding Organizer and Planner

\begin{abstract}
Abstrak
Sebuah perusahaan wajib memiliki logo sebagai identitas agar dapat dikenal oleh masyarakat sebagai konsumen untuk mengkonsumsi produk yang mereka jual. Redesign logo pada sebuah perusahaan Duta Minang Wedding Organizer and Planner, yang beralamat di Jl. Rajawali No 09 Padang. dilakukan jika logo lama tersebut sudah tidak memenuhi syarat, di antaranya: (1) sudah tidak layak untuk dipakai pada media penerapan; (2) adanya perubahan visi dan misi perusahaan; (3) penggunaan logo yang tidak sesuai fungsi sebagai mana mestinya; (4) tidak efektifnya logo untuk dikenali oleh masyarakat; dan (5) hingga tidak konsistennya bentuk logo untuk dipergunakan pada media-media yang akan menjadi tempat promosi bagi perusahaan. Sama seperti halnya Duta Minang Wedding Organizer and Planner yang memang sudah meninggalkan logo pada beberapa penerapan media, dan lebih mengunggulkan nama perusahaan saja agar dikenal oleh masyarakat dan menerapkan nama tersebut pada beberapa media cetak. Maka perlu dilakukannya desain sebuah logo mengenai Duta Minang Wedding Organizer and Planner. Dalam desain logo Duta Minang Wedding Oragnizer and Planner ini perancang menggunakan metode analisis AIDA guna logo sebagai alat promosi yang harus menarik perhatian, mendapatkan dan mendorong minat, membangkitkan keinginan, dan mengasilkan tindakan terhadap produk. Sebagai identitas dari perusahaan maka logo diperlukan bentuk desain yang simple, mudah diingat, fleksibel dan dinamis. Logo sebagai visual identity untuk menciptakan untuk potitioning product dalam bentuk benak target audiens dan penciptaan logo yang baru akan membangun image masyarakat kepada Duta Minang Wedding Organizer and Planner. Tujuan dari perancangan desain logo Duta Minang Wedding Organizer and Planner agar tercapainya keinginan Duta Minang Wedding Organizer and Planner menjadi perusahaan layanan jasa dengan perlengkapan dan peralatan yang lengkap dan dicari di Kota Padang. Redesign logo perusahaan ini dapat membentuk karakter baru dari perusahaan yang disertai dengan perubahan visi dan misi baru yang digunakan saat ini.
\end{abstract}

Kata kunci : Desain, Logo, Duta Minang Wedding Organizer and Planner 


\section{Pendahuluan}

Redesign logo ini diperlukan untuk perusahaan layanan jasa Duta Minang Wedding Organizer and Planner agar dapat dikenal dengan mudah oleh masyarakat yang akan menjadi taget audiens. Seperti yang diketahui logo lama sudah tidak komunikatif untuk sampai dikenal dan diingat publik sebagai identitas perusahaan. Redesign juga diciptakan agar masyarakat dapat membedakan Duta Minang Wedding Oraganizer and Planner dengan kompetitornya. Selain itu agar masyarakat mengenal Duta Minang Wedding Oraganizer and Planner sebagai perusahaan wedding organizer di Kota Padang yang memiliki fasilitas lengkap untuk sebuah perencanaan pernikahan, dan dapat dikenal.

Melakukan redisign untuk Duta Minang Wedding Oraganizer and Planner dilihat dari logo lama memiliki gagasan Minangkabau selalu menggunakan lambang Tangkuluak Tanduak Kabau (Tengkuluk Tanduk Kerbau) sebagai tengkuluk hiasan di kepala wanita di Minangkabau sebagai pengantin, maupun Gonjong Rumah Gadang dan tagline memiliki font yang tidak bisa di baca karena penggabungan karakter font yang biasa dengan bintang. Hal ini menyebabkan logo lama terkesan kuno dan monoton pada identitas Minangkabau adalah Gonjong Rumah Gadang, Tangkuluak Tanduak Kabau, dan Tanduak Kabau (tanduk kerbau).

Logo yang digunakan Duta Minang Wedding Organizer and Planner selama ini juga sudah tidak digunakan sebagai mana fungsi yang sebenarnya, dan dianggap sudah tidak sesuai lagi dengan visi dan misi sekarang, terkesan kuno, jika dibandingkan dengan zaman modern sekarang. Duta Minang Wedding Oraganizer and Planner menempatkan logo pada beberapa media pendukung sebagai tempat promosi tidaklah efektif untuk ditempatkan. Sebab Duta Minang Wedding Oraganizer and Planner hanya menggunakan logo pada media brosur saja, dan untuk media berukuran besar lainyya Duta Minang Wedding Oraganizer and Planner tidaklah konsisten dengan bentuk logo yang ada. Sebab hanya menggunakan font nama untuk Duta Minang Wedding Oraganizer and Planner dan berubahubah. Baik dari segi font, warna, ukuran dan media itu sendiri.

Berdasarkan uraian di atas perlu dilakukan sebuah proses kreatif yang merujuk pada permasalahan dan keinginan dari Duta Minang Wedding Organizer and Planner sendiri. Proses kreatif yang akan dilakukan adalah merancang kembali (redesign) logo perusahaan Duta Minang Wedding Organizer and Planner. Menurut Helmi, 2008, Redesign merupakan perencanaan dan perancangan kembali suatu karya agar tercapai tujuan tertentu (Churchman and Ackolt dalam Irfan, 202: 1-1) redesign adalah suatu proses untuk menentukan tindakan-tindakan dimasa depan yang sesuai, melalui suatu tahapan pemilihan.

Berdasarkan identifikasi masalah yang dipaparkan di atas, maka ditemukan sebuah masalah yaitu: Bagaimana me-redesign logo Duta Minang Wedding Organizer and
Planner sesuai dengan visi dan misi perusahaan guna sebagai identitas dan dapat dibedakan dari perusahaan lain yang memiliki produk yang sama?

Tujuan dari penciptaan ini adalah me-redesign logo Duta Minang Wedding Organizer and Planner sesuai dengan visi dan misi perusahaan guna sebagai identitas, dapat dibedakan dari perusahaan lain yang memiliki produk yang sama, mencegah pembajakan produk dan dapat mengkomunikasikan informasi seperti keaslian, nilai dan citra dari perusahaan.

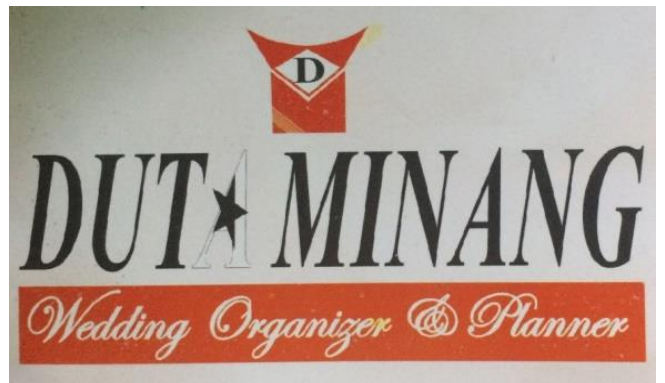

Gambar 1. Logo Lama Duta Minang Wedding Organizer and Planner. Sumber: Melisa Suardi, 2018

Perancangan redesign logo bertujuan sebagai pembanding antara logo kompetitor yang ada dan menjadi pusat perhatian untuk khalayak dapat mengenal kembali Duta Minang Wedding Organizer and Planner kedepannya sebagai vendor dekorasi pesta pernikan.

Selain itu dengan dilakukannya proses perancangan ini, diharapkan Duta Minang Wedding Organizer and Planner bisa memperluas jangkauan kerjasama dengan klien maupun vendor wedding organizer lainnya yang tidak hanya di Kota Padang. Tahapan peninjauan karya ini bertujuan untuk menghindari dan meminimalisir kemiripan maupun kesamaan dari bentuk-bentuk visual yang sudah dirancang sebelumnya. Dengan dilakukannya tahapan ini, perancang berharap logo yang akan dirancang untuk Duta Minang Wedding Organizer and Planner tidak menyerupai logo kompetitor dalam bidang yang sama.

\section{Pembahasan}

\section{A. Metode dan Konsep Garapan Karya}

Realisasi konsep merupakan tahapan untuk perancangan sebuah logo. Menurut Swasty (2016: 124), logo dapat menggambarkan semua atribut non-fisik seperti visi misi, nilai, kepribadian dan budaya perusahaan. Sedangkan menurut Rustan (2017: 13), logo adalah elemen gambar atau simbol pada suatu identitas visual. Pada pemaparan data mengenai logo lama Duta Minang Wedding Organizer and Planner maka akan disusun beberapa konsep mengenai perancangan ulang atau redesign untuk logo Duta Minang Wedding Organizer and Planner yang baru. Menentukan landasan awal sebuah ide untuk perancangan serta keterkaitan terhadap rancangan logo yang baru. Menjadikan satu makna dari beberapa deskripsi dari perusahan, visi dan 
misi, serta keinginan perusahaan dan menjadikan konsiten fungsi logo sebagai identitas baru yang dapat lebih mudah dikenali pada setiap media yang terkait.

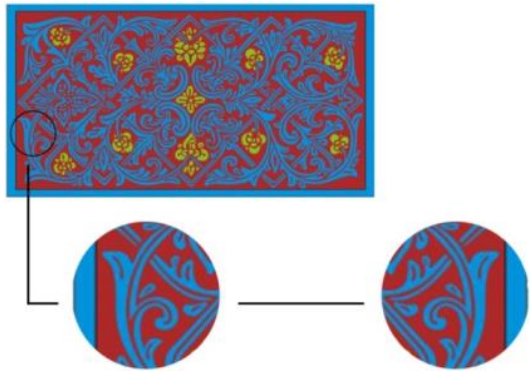

Gambar 2. Ukiran Saluak Laka.

Dokumentasi: Melisa Suardi, 2018.

Disini peracangan menggunakan ukiran Saluak Laka sebagai landasan awal sebuah perancangan logo Duta Minang Wedding Organizer and Planner, dimana Saluak Laka memiliki makna arti yang sama dengan visi dan misi Duta Minang Wedding Organizer and Planner jalani sekarang, yaitu kekerabatan, keterkaitan, dan tanggungjawab. Menggunakan bentuk ukiran Saluak Laka sebagai bentuk elastisitas perusahaan dalam memenuhi keinginan klien untuk dekorasi pernikahannya.

Mengkombinasikan ukiran Saluak Laka dengan identitas perusahaan dan mewujudkannya menjadi logo yang baru sebagai wajah perusahaan menyesuaikan perkembangan zaman. Dan penempatan typografi yang sesuai untuk nama perusahaan yang akan mewujudkan bentuk logo, dengan penggabungan logotype dan logogram yang akan mudah dikenal masyarakat, baik dari penglihatan, tingkat baca, dan mudah diingat.

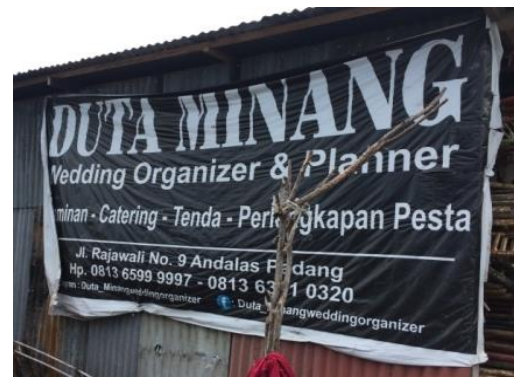

Gambar 3. Nama Duta Minang Wedding Organizer Pada Spanduk Tanpa Logo.

Dokumentasi: Melisa Suardi, 2018.

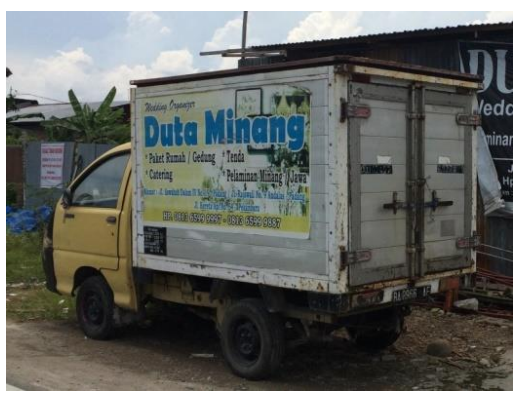

Gambar 4. Nama Duta Minang Wedding Organizer Pada Mobil Box Tanpa Logo Asli. Dokumentasi: Melisa Suardi, 2018.

\section{B. Defenisi Logo}

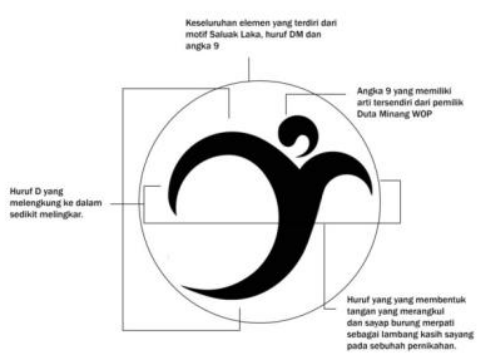

Gambar 5. Logo Terpilih. Rancangan: Melisa Suardi, 2018.

Logogram ini dipilih karena lebih menyesuaikan antara motif dari Saluak Laka denga visi dan misi yang dijalankan oleh Duta Minang Wedding organizer and Planner. Mengkombinasikan antara motif dengan huruf D dan M. Menyatukan huru D pada motif Saluak Laka, dengan bentuk melengkung lebih besar pada bagian kiri, menyesuaikan anatomi dari huruf D itu sendiri. Dimana huruf D lebih menjelaskan Duta dan bentuknya sedikit melingkar yang mengartikan tiga elemen yang tidak terputus antara perusahaan, produk dan konsumen. Lalu huruf $\mathrm{M}$ yang membentuk menyerupai tangan yang merangkul dan seperti sayap burung merpati sebagai lambang kasih sayang pada sebuah pernikahan. Pada bagian atas terdiri dari satu motif tunggal yang menjelaskan bahwa motif tersebut adalah bentuk angka sembilan. Yang mana angka sembilan memiliki arti tersendiri dari Duta Minang Wedding Organizer and Planner, dan juga terdapat pada logo sebelumnya. Digambarkan dari sembilan garis kecil pada logogram.

\section{Aplikasi Warna}

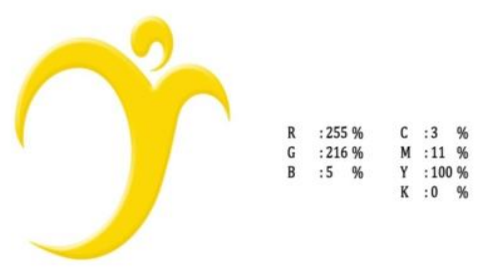

Gambar 6. Terapan Warna Logo Terpilih. Rancangan: Melisa Suardi, 2018.

Adapun untuk perancangan logo Duta Minang Wedding Organizer and Planner perancang menggunakan warna kuning untuk mewakili emas yang berkarakter kuat, elegan, mewah dan tangguh. Warna pada bunga matahari sebagai referensi warna dan bentuk yang sesuai dan mewakili karakter perusahaan Duta Minang Wedding Organizer and Planner. 


\section{Media Pendukung \\ 1. Baliho}

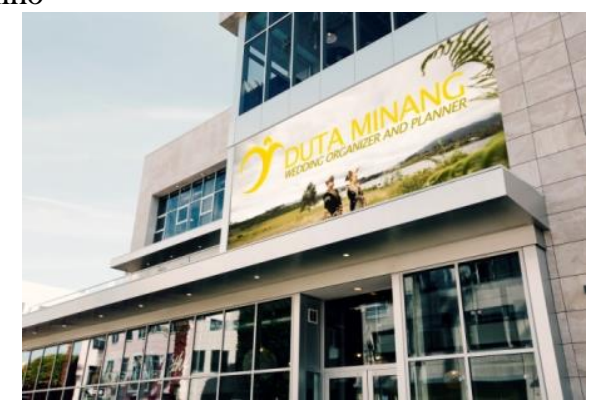

Gambar 7. Aplikasi Media Baliho

Rancangan: Melisa Suardi, 2018.

Baliho merupakan suatu sarana atau media promosi yang memiliki unsur memberitakan informasi event atau kegiatan yang berhubungan dengan masyarakat luas, selain itu baliho juga digunakan untuk mengiklankan suatu produk baru. Baliho dapat juga diartikan sebagai suatu media untuk promosi yang di cetak menggunakan print digital umumnya berbentuk portrait maupun vertical.

Fungsi baligho sendiri adalah untuk memberitahukan atau menyampaikan pesan iklan atau promosi yang disampaikan lewat media kain, vinyl, sticker, atau semacamnya sebagai media untuk diberitahukan kepada masyarakat (pasar)

Dalam ilmu Desain Komunikasi Visual, baliho merupakan media yang cukup penting dan strategis untuk menerapkan hasil desain, baik dalam bentuk promosi maupun dalam bentuk iklan produk. Media baliho juga dikenal lebih efektif untuk memperkenalkan suatu produk dan merk tertentu.

Pada perancangan ini, media baliho sengaja dipilih agar audiens atau konsumen dapat melihat dan mengetahui lebih jelas mengenai Duta Minang Wedding Organizer and Planner. Dengan demikian

2. Bilboard

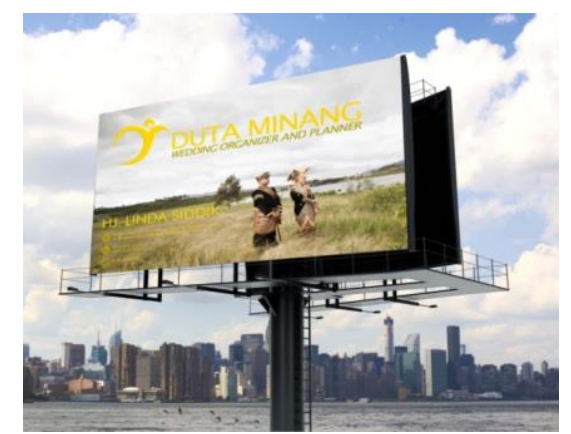

Gambar 8. Aplikasi Media Billboard

Rancangan: Melisa Suardi, 2018.

Secara bahasa Billboard artinya Papan Iklan, maksudnya papan berukuran besar dimana papan tersebut diberi tulisan atau gambar muatan iklan, pengumuman atau promosi. Billboard merupakan bentuk promosi iklan luar ruang dengan ukuran besar, bisa disebut juga billboard ialah bentuk poster dengan ukuran yang lebih besar yang diletakkan tinggi di tempat tertentu yang ramai dilalui orang. Billboard termasuk salah satu model iklan di luar ruang atau outdoor advertising yang paling banyak dipakai untuk promosi suatu produk.

Billboard memiliki fungsi yang cukup efisien dan efektif untuk menyampaikan informasi dan promosi sebuah produk, di samping ukurannya lebih besar, posisi penempatannya juga lebih strategis sehingga dapat dilihat oleh masyarakat luas.

Pemilihan billboard sebagai salah satu media untuk menerapkan logo dan merk Duta Minang Wedding Organizer and Planner, bertujuan agar logo dan merknya tersebut dapat dikenali oleh Target Audines atau konsumen secara capat dan jelas, sehingga Brand dari Duta Minang melekat pada masyarakat atau konsumennya.

Dengan demikian redesign logo pada Duta Minang dapat mencapai tujuan dan target sasaran yang diinginkan sehingga dapat meningkatkan daya saingnya dengan usaha sejenis.

3. Brosur

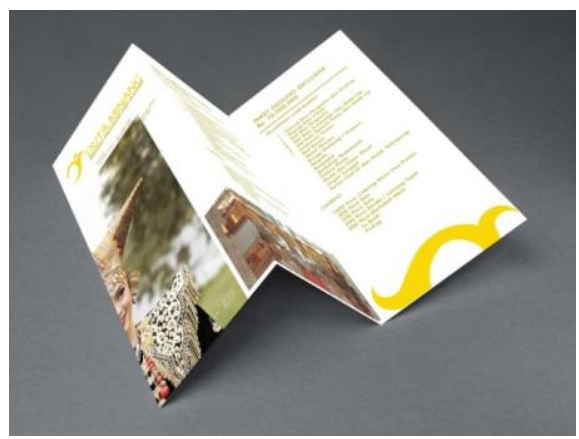

Gambar 9. Aplikasi Media brosur Rancangan: Melisa Suardi, 2018.

Brosur secara umum diartikan sebagai salah satu media untuk mempromosikan barang, jasa dan sebagainya. Brosur terbuat dari kertas dengan ketebalan 80 gr hingga 100 gr yang di dalamnya memiliki sejumlah informasi serta penawaran tentang jasa ataupun produk tertentu. Adapula pengertian yang lain mengenai brosur yakni sebuah alat publikasi yang resmi dari sebuah perusahaan yang mempunyai bentuk cetakan, yang memiliki berbagai informasi tentang sebuah produk, layanan, program dan yang lainnya, dan ditujukan pada pasar sasaran dan juga sasaran tertentu yang lainnya.

Untuk media promosi dan iklan media brosur lebih lengkap dibandingkan dengan media-media lainnya, seperti baliho dan billboard. Tidak jarang media brosur juga memuat tentang sejarah ataupun profil sebuah perusahaan maupun produk yang bertujuan untuk meyakinkan konsumen.

Berangkat dari penjelasan tersebut, adapun pemilihan media brosur sebagai salah satu media yang digunakan untuk menerapkan redesign logo Duta Minang ini agar lebih dikenal lagi oleh target audien. Selain itu diharapkan juga dapat meningkatkan pelanggan sebagai Wedding Organizer. 


\section{Gelas}

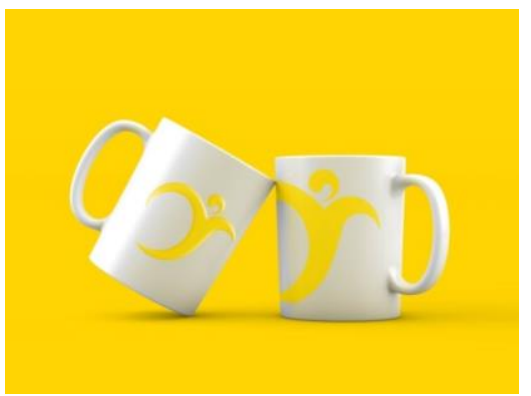

Gambar 10. Aplikasi Media gelas

Rancangan: Melisa Suardi, 2018.

Gelas atau sering juga disebut sebagai mug coating, merupakan bagian dari salah satu media pendukung baik dalam promosi iklan produk dan perusahaan. Mug merupakan sejenis cangkir untuk wadah air minum bagi masyarakat. Oleh karenanya keberadaannya tidak dapat dipisahkan dari kebutuhan manusia.

Dalam desain Komunikasi Visual, mug selalu digunakan sebagai media pendukung untuk menerapkan desain baik berupa promosi produk maupun perusahaan. Sebagai media pendukung dalam DKV, mug dapat dikategorikan sebagai marchandise atau cenderamata yang biasanya diberikan kepada konsumen sebagai hadiah telah berlangganan dengan perusahaan atau produk tertentu.

Dalam konteks perancangan ini, dipilihnya mug sebagai media cenderamata tidak terlepas dari alasan yang telah penulis jelaskan di atas. Melalui media tersebut tentunya diharapkan logo yang telah dirancang kembali dapat dikenali dan selalu diingat oleh konsumen atau target audiens.

5. Kartu Nama

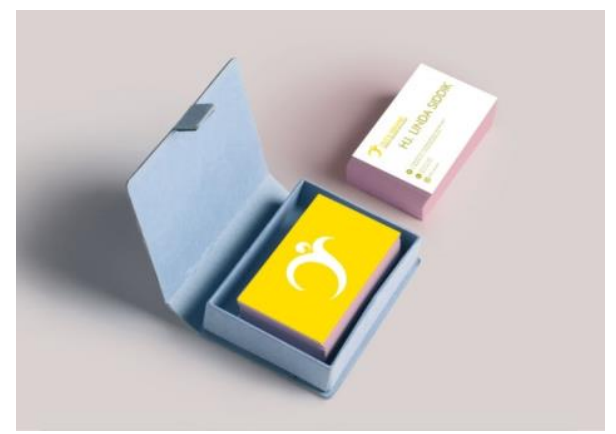

Gambar 11. Aplikasi Media Kartu Nama

Rancangan: Melisa Suardi, 2018

Kartu nama atau sering juga disebut dengan Id Card merupakan kartu identitas diri dan perusahaan yang biasanya diberikan kepada kenalan dan pelanggan dari perusahaan. Kartu nama merupakan salah satu media pendukung untuk promosi produk atau perusahaan yang sampai saat ini masih dianggap efektif.

Adapun manfaat kartu nama sebagai media promosi di antara adalah :

1. Untuk profil Diri

2. Informasi Perusahaan atau bisnis

3. Personal Branding yang exclusive
Oleh karena itu, melihat fungsinya sebagai media pendukung dalam promosi usaha, maka dipilihlah kartu nama sebagai salah satu untuk menerapkan redesign Duta Minang, yang tentunya dapat meningkatkan brand usaha itu sendiri sehingga dapat meningkatkan pelanggan atau konsumen untuk mepercaya Duta Minang sebagai Wedding Organizer.

\section{Kesimpulan}

Dari perancangan redesign logo Duta Minang Wedding Organiser and Planner, merupakan pemecahan masalah terhadap logo yang lama yang sudah dianggap tidak komunikatif lagi dengan target audien, sehingga tidak dapat membangun brand dari perusahaan itu sendiri. Faktor ini tentunya akan berpengaruh terhadap pesaingnya sehingga untuk menjaga positioning perusahaan diperlukan redesign yang baru terhadap perusahaan Duta Minang Wedding Organiser and Planner.

Adapun konsep redesign logo Duta Minang tersebut mengangkat motif ukiran saluak laka. Saluak Laka memiliki makna arti yang sama dengan visi dan misi Duta Minang Wedding Organizer and Planner yaitu kekerabatan, keterkaitan, dan tanggungjawab. Menggunakan bentuk ukiran Saluak Laka sebagai bentuk elastisitas perusahaan dalam memenuhi keinginan klien untuk dekorasi pernikahannya.

Untuk warna logo, penulis menggunakan warna kuning untuk mewakili emas yang berkarakter kuat, elegan, mewah dan tangguh sehingga dapat membangun branding perusahaan Duta Minang itu sendiri. Sedangkan media pendukung yang digunakan di antaranya adalah baliho, bilboard, brosur, mug, dan kartu nama.

\section{Daftar Pustaka}

Arsyad, Azhar. 2011.Media Pembelajaran.cetakan ke15.Jakarta: Rajawalli Pers.

Azrial, Yulfian. 1995. Keterampilan Tradisional Minangkabau. Padang: Angkasa Raya

Danton, Sihombing. 2001. Tipografi Dalam Desain Grafis. Jakarta: Gramedia

Effendy, Onong, 1994, Ilmu Komunikasi: Teori dan Praktek, Bandung: Remaja Rosdakarya

Hadi, Sutrisno 1984. Bimbingan Menulis Skripsi Thesis. Jilid Pertama, Yayasan penerbitan Fakultas Psikologi UGM, Yogyakarta.

Hanafie, M Rizki, Padang. 2015. Perancangan Event Jambore Mapala Se Kota Padang: Skripsi

Jones, Christophe. 1969. Design Methods.

Klimchuk, Marianne Rosner dan Krasovec, Sandra A. Packaging Design:Successful Product Branding from Conceptto Shelf. New Jersey: John Wiley \& Sons, Inc.

Kotler, Amstrong. 2001. Prinsip-prinsip Pemasaran. Edisi Keduabelas, Jilid 1, Jakarta: Erlangga 
Kurniawanto, A. 2007. Pengantar Desain Komunikasi Visual. Yogyakarta: Andi Offset.

Kusrianto, Adi. 2006. Pengantar Desain Komunikasi Visual. Yogyakarta: Andi

M. Sayuti Dt. Rajo Penghulu. 2005. Tau Nan Jo Ampek (Pengetahuan Yang Empat Menurut Ajaran Budaya Alam Minangkabau). Padang: Mega Sari Kerjasama Sako Batuah

Riduwan. 2010. Metode dan teknik Menyusun Tesis. Bandung: ALFABETA.

Rustan, Surianto, 2009, Layout, Dasar dan Penerapannya. Jakarta: PT. Gramedia Pustaka Utama.

Rustan, Surianto. 2017. Mendesain Logo. Gramedia: Jakarta

Sachari, Agus . 2005. Metode Penelitian Budaya Rupa. Jakarta: Erlangga

Saputra, Afrianto, Padang. 2015. Perancangan Company Profile Sweet Tooth Cafe Padang: Skripsi

Supriyono, Rahmat. 2010. Desain Komunikasi Visual Teori dan Aplikasi. Yogyakarta: Andi

Yelly, Nofroza (2012),'Pertunjukan Saluang Orgen Pada Masyarakat Nagari Silayo Kabupaten Solok", Tesis, ISI Padangpanjang. 